\title{
Medical hybridity and beyond: professional transitions in Italian outpatient settings
}

\author{
Federico Sofritti ${ }^{1}$
}

Accepted: 16 November 2020 / Published online: 7 December 2020

(C) The Author(s) 2021

\begin{abstract}
The marketization of public healthcare has brought about organizational transformations, affecting health professionals' ways of working in hospitals and outpatient organizations. As a result of the reforms in the 1990s, the principle of business-like healthcare has been introduced in the Italian health system. This paper presents the main findings of a study of specialist doctors working in two local health organizations in the Tuscany region. Drawing on semi-structured interviews with specialist doctors working in an outpatient setting, the article examines the manifold reactions to changes of the medical profession within outpatient settings. In particular, the combination of professional and organizational dimensions has been taken into consideration. The results show that a change is involving outpatient specialist doctors' identity: organizational change affects several dimensions of the medical professional ethos. The change has been understood by categorizing three major types of approaches to medical professionalism, which are aimed to understand the complexity of the domain and to summarize professionals' reactions: the first is linked to a traditional model of professionalism; the second accepts partially business-like organizational issues, while trying to create individual spaces of autonomy in daily tasks; the third co-opts new organizational issues, which become part of the medical professional ethos.
\end{abstract}

Keywords Medical profession · Healthcare reforms · Organizing professionalism · Hybridity · Managerialism · Professional identity

Federico Sofritti

f.sofritti@staff.univpm.it

1 Department of Economic and Social Sciences (DISES), Polytechnic University of Marche,

Piazzale Martelli 8, 60121 Ancona, Italy 


\section{Introduction}

European healthcare systems have undergone significant reform in the last few decades (Giarelli 2003; Giarelli and Giovannetti 2019; Numerato et al. 2012). Market-oriented reforms have introduced New Public Management (NPM) as a primary organizational technique throughout the public sector (Bezes et al. 2011; Cascòn-Pereira et al. 2016; Noordegraaf 2016; Pollitt and Bouckaert 2011). With the process of marketization, local health organizations have been turned into public enterprises and the principle of managerialism has been introduced within the healthcare domain. These dynamics have triggered changes affecting healthcare organizations as well as healthcare professionals. Consequently, professional and organizational logics are gradually blending, changing professionals' everyday practices and ways of working (McDonald et al. 2013).

Since the early 1990s, the Italian National Healthcare System (NHS) has been significantly reformed: in line with the general neoliberal climate, between 1992 and 1999 a business-like logic was introduced in healthcare organizations (Vicarelli 2017). NPM-inspired principles have introduced managerialism in public healthcare settings. As a result, organizational duties have been added to the traditional clinical tasks of medical doctors. The reorganization raises questions about the medical profession's reaction to such changes (Freidson 1986, 2002; Tousijn 2008).

This paper focuses on the consequences of public health reforms on professionals working in outpatient settings within the Italian NHS. The aim is to provide an overview of how organizational change has affected medical specialists' perceptions within territorial organizations in one regional context. The article presents the main findings of an exploratory study based on semi-structured interviews with medical doctors working in outpatient settings in the Tuscany region. In this regard, medical doctors' perceptions and points of view in relation to the impact of marketization of the Italian NHS on their profession were taken into account.

\section{The theoretical debate: understanding the effects of reforms on medical doctors}

The introduction of business-like logic in healthcare produced an interplay of two on-the-job cultures: occupational professionalism and organizational professionalism (Evetts 2011). The first, typical of the public sector (Hanlon 1999), is associated with traditional professionalism, which consists of decisional autonomy, patient trust and medical paternalism (Dubar and Tripier 1998; Freidson 1970, 2001; Parsons 1939). The second, typical of the private sector, is based on organizational imperatives and sets strict boundaries that professionals must respect. These two cultures differ with respect to values, norms and motives, and their interaction creates professional hybrids by challenging traditional established 
boundaries (Carvalho 2014; Noordegraaf 2007). Professionalism and managerialism, as forms of institutional logic, provide professionals and managers with frames of reference and sense of identity (Reay and Hinings 2009; Waring 2015). This stimulates doctors to adapt their practices to new organizational issues and to manage their work differently (Denis and van Gesten 2016).

Research has focused on the effects of public health reforms on physicians, particularly on the relationship between managerialism and professionalism. Initially, doctors and managers were defined as two different "speech communities" (Parker and Dent 1996): therefore, the relationship between medicine and management has been considered a zero-sum game, the consequence of which has been the colonization of healthcare by management. Subsequent studies have theorized the idea of "blurring boundaries" between healthcare organizations and professions, as a result of processes like the "co-optation" of doctors in managerial roles (Andersson and Liff 2018; Tousijn 2013; Numerato et al. 2012; Salvatore et al. 2018). In this regard, two research strands can be identified.

The first research strand addresses the relationship between professionalism and managerialism in terms of a zero-sum game. From this perspective, organizational changes in healthcare weaken physicians' professional autonomy (Filc 2006; Harrison and Ahmad 2000; Sandstrom 2007). As a result, "medical dominance" in healthcare is considered to be in decline (Navarro 1998). Therefore, the emphasis on organizational principles could create the basis for a deprofessionalization of medical doctors, whose practice is increasingly bureaucratic and routine-oriented (Ritzer and Walczak 1988).

The change significantly affects medical doctors, creating conflicting subgroups with corresponding subcultures: "financial realism" and "clinical purism". The first is typical of doctors-in-management, who tend to prioritize organizational and economic principles, whereas the second has spread among clinical doctors, who prioritize patients' needs and professional ethics (Martinussen and Magnussen 2011).

The second research strand aims to investigate the strategic reactions of doctors to managerialism: the idea of hybridization of work subcultures is maintained, instead of their polarization. (Noordegraaf 2007, 2015; Salvatore et al. 2018; Olakivi and Niska 2017; Tousijn 2013; Waring 2015). In this perspective, organizational change is not considered a threat for doctor's autonomy; rather, it prompts a renewed professionalism within a different context (Tonkens et al. 2013). The introduction of business-like logics into the healthcare sector is considered a manifold phenomenon, whose effects could change depending on institutional context and the professionals involved (Andersson and Liff 2018; Correia 2013; Kirkpatrick et al. 2016).

Responses can vary from acceptance to a refusal of the principles of marketization (Numerato et al. 2012). Strategic reactions of the medical profession can be placed on a continuum, whose extremities are the acceptance of organizational issues, and, on the opposite pole, their rejection. Between acceptance and rejection several nuanced reactions exist (Waring and Currie 2009).

Professionalism and managerialism can interact and affect each other (Tousijn 2012). Management-led practices and clinical governance can bring about changes in professional practice and values until the deployment of a reframing of professional identity. As a result, professional practice is a matter of negotiation, since 
clinicians need to introduce organizational issues in their everyday tasks, taking into consideration, for example, the time and money spent carrying out their job (Kuhlmann et al. 2011).

Emerging "professional-managerial hybrids" (Waring 2014) show a reframing of boundaries and identities between medicine and management (Doolin 2002) in terms of in-between managerial and clinical mindsets (Spehar et al. 2014). Organizational change and professional strategies seem to be path-dependent, as they interact with social, historical and institutional contingencies (Spehar et al. 2012). More recently, the concept of "organizing professionalism" has enriched this second strand opening a post-hybridity scenery (Noordegraaf 2015). In this perspective, organizing becomes part of professional practice and identity, whereas the idea of hybridity entails a combination of organizational and professional logics. Hybrid professionalism mediates between competing logics, whereas organizing professionalism embeds organizational logics and skills in professional practice. In other words, managerialism and professionalism become part of a coherent sense of self (Bévort and Suddaby 2016).

\section{The reforms of the Italian NHS: a brief overview}

The Italian National Health Service (Servizio Sanitario Nazionale), created in 1978, is based on a "universalistic institutional" principle of healthcare provision: the state is considered responsible for providing healthcare assistance to citizens (Vicarelli 2019). During the 1990s, the Italian health system underwent a number of reforms, triggering a process of marketization and introducing NPM-inspired management techniques.

With the reforms enacted between 1992-1993 and 1999 (Decrees 502/1992, 517/93 and 229/99), local health organizations and public hospitals acquired the name of Aziende Sanitarie Locali (local health trusts) and Aziende Ospedaliere (hospital trusts); they have been turned into trusts from a legal and administrative perspective.

These reforms had three main aims (Vicarelli and Pavolini 2017): the first was to put local health organizations and hospitals under regional control; the second was to separate healthcare management from local politics; the third was to regulate medical practice through stricter managerial tools (Vicarelli 2015). In particular, reforms asked for resources containment, and greater effectiveness and appropriateness by overcoming the paternalistic and doctor-centerd relationship with patients. The principle of managed care was introduced, based on the transition from medical dominance to stricter mechanisms of control of professionals (Vicarelli 2012). As a result, managerialism is one of the main factors of change, as it attempts to standardize the domain by introducing organizational mechanisms-such as DRGs, performance monitoring and target-setting-and clinical ones, such as evidence-based medicine, medical guidelines and Continuing Professional Development (Kuhlmann et al. 2011). The aim of the process of standardization is to reduce professional autonomy to control and evaluate medical performance. 
Another feature of the reforms is the growing importance of territorial healthcare through the introduction of the Chronic Care Model, based on the principle of health and social care integration. The main strategy is the integration between hospital and outpatient healthcare (Benci 2009) by enhancing the autonomy of the district as main organizational "bridge" between hospitals and territorial organizations. In particular, the 1999 reform highlighted the importance of overcoming a hospitalcentered idea of healthcare provision (Giarelli 2019).

Historically, these two settings have different features within the Italian NHS: hospital services rely on a bureaucratic logic and professionals must comply with rigid administrative limitations. As a result, professional roles are strictly divided and aimed at providing standardized services.

Territorial organizations rely on a network logic aimed at providing multiple services for a heterogeneous population. Primary care and outpatient services are part of this setting (Maino 2001), as they connect hospital and territorial healthcare provision. Organizational culture and professional routines are more flexible and less structured; yet, reforms have increased the bureaucratization of this domain by setting stricter schedules, bureaucratic procedures, performance monitoring for professionals. In particular, they are required to comply with time and budget limitations (e.g., in prescribing further specialist examinations) established by local health trusts.

\section{Research context and methodology}

The aim of the study is to explore the points of view of specialist doctors working in outpatient settings regarding the reconfiguration of healthcare and the perceived effects of reforms on their mindsets and ways of working.

The reaction of Italian professionals to managerialism has been investigated mainly in hospital settings, where it seems slow and not yet effective (Lega and Sartirana 2016). Also, the response shows different patterns, depending on professionals' role and form of job contract they have with the NHS (Vicarelli and Pavolini 2017).

Following the second research strand earlier identified, a main hypothesis of the study was that the processes of marketization of the Italian NHS are leading to changes in the professional identities, ethics and mindsets of medical doctors. In particular, the idea was that a hybridization of their professional practices and identities was ongoing. Another hypothesis was that reactions to change are manifold; this is the reason why it is considered of interest to gain a better understanding of doctors' experience of the changes using a qualitative approach.

The fieldwork was conducted in the Tuscany region in Italy in 2015. The regional health system in Tuscany is based on a universalistic model offering coverage to all citizens and residents; also, it has been one of the most responsive regions to the reforms (Pavolini and Vicarelli 2013). In particular, the regional government has adopted organizational measures to implement an Expanded Chronic Care Model, emphasizing the territorial level of primary care and promoting health and social integration care 
practices (Tousijn 2012). The empowerment of the territorial dimension has affected all professionals involved in such organizations, including medical doctors.

At the time of carrying out the field research, the Tuscany region was composed of 12 local health trusts. The local trust of Florence was selected as it represents the institutional center of Tuscan healthcare and is one of the biggest health trusts at a national level, comprising 33 municipalities. The trust in Pistoia is medium-sized and comprises 22 municipalities. These areas were chosen to investigate different contexts in the same region.

The findings are not intended to be representative for all the medical doctors working in the Italian NHS. Considering the explorative design of the study, a qualitative approach was considered appropriate: semi-structured qualitative interviews were used to collect data.

In total, 30 specialist doctors involved in clinical roles were recruited and interviewed. The inclusion criteria set for the participants were holding a medical specialization (postgraduate-degree in medicine) and working in outpatient settings.

Theoretical sampling was used, based on the principle of developing interpretations during the research. Participants were selected in itinere until theoretical saturation had been achieved (Kelly 2010). Before the recruitment of participants, a series of seven interviews with key informants (representatives of medical trade unions and health middle managers) was conducted to better understand the context. Furthermore, the interviews provided insights into how to improve the construction of the interview guidelines.

Interviews lasted for $45 \mathrm{~min}$ on average and were recorded and transcribed verbatim. All the interviews were conducted in Italian and the extracts in this article were translated by the author. Thematic analysis was carried out to examine the outcomes of healthcare reforms on the dimensions of clinicians' professional identity in more depth. Interviews were intended to examine the discourse on organization present in the respondents' narratives and what sense of being a doctor was perceived in the renewed context of the healthcare service.

Thematic categories were constructed on the basis of a threefold perspective: professional, organizational and personal. Finally, professional and organizational perspectives were combined to identify three approaches to the profession.

The analysis followed four steps: (1) reading the transcriptions to develop an overall idea; (2) identifying units of meaning in relation to each analytical dimension; (3) condensation of the units of meaning dealing with professional and organizational dimensions, forming three kinds of reactions to organizational change; and (4) generalizing the results of point 3 . The three approaches identified are not intended to be exhaustive; instead, they represent an attempt to conceptualize the outcomes of business-like healthcare in terms of medical professionals' identities. The main findings are presented with quotations and details of the respondents' clinical specialization, gender and age. 


\section{Findings}

The analysis of professional and organizational dimensions enabled the categorization of three approaches to the profession among specialist doctors working in the contexts examined during the field research: the "traditional" doctor, the "liminal" doctor and the "corporatized" doctor. The three approaches can be placed on a theoretical continuиm ranging from traditional professionalism to corporatized professionalism. The approaches are not mutually exclusive as they mixed between the single interviews.

\section{Three approaches to the profession}

The traditional doctor's reaction to organizational change is mainly resistance: the need to follow clinical logic is deemed the first principle of everyday practice. Hence, a conflict between classic professionalism and business-like healthcare is perceived and often becomes grounds for the refusal of managerial guidelines. This reaction is linked to classic professionalism and, therefore, to a form of ethics based on the values of the Hippocratic oath. Also, our data suggest that this approach seems more common among older generations of professionals; this is probably due to the fact that their professional socialization took place in a less 'managerialized' professional context. Therefore, professional identity is characterized by "occupational professionalism" (Evetts 2006; 2011) issues and there is no space for marketinspired and organizational principles in the mindset of this doctor.

The values of the profession are still the same: I don't think that they change over time. I mean, according to me the values of the medical profession consist of attending to patients with conscience and humanity [Dermatologist, female, 64]. As for myself, possessing clinical competences is enough. The fact that professionals need to possess managerial skills is extemporaneous. It's like an evening course of marketization [Psychiatrist, male, 57].

There is a clear refusal of standardized protocols and guidelines, seen as obstacles to professional practice and autonomy, which is inviolable. From this perspective, being a physician is a 'mission': the doctor-patient relationship is its cornerstone and the pursuit of health is the main and only goal.

You need to know what you do, so the guideline is useful until a certain point [...]. But, if you are a doctor, you put yourself on the line every day and, sometimes, you make decisions not complying with the guidelines [...]. You attend to patients and you work as doctor according to your conscience and your experience. All things considered, you cannot follow the guideline strictly, because, in that case, you are not a doctor [Oculist, female, 59].

The relationship with patients is personal, trustworthy and paternalist: there is marked information asymmetry between clinicians and patients. The latter need to put their personal health in doctors' hands. Therefore, this type of doctor claims the 
need to possess only clinical skills and to continuously update clinical knowledge and competences. This is considered enough to be a good professional.

According to me, doctors' competences do not change: the doctor needs to learn more. He needs to keep up-to-date systematically from the clinical point of view. Thus, competences do not change; they need to be deeper, if you will. [Surgeon, male, 63].

Healthcare organization is seen as a hierarchical structure, where the doctor is at the top and has the right to organize other health professionals' jobs. Professional jurisdictions are clear and well-defined: the doctor is 'dominant' and in a higher position.

The reorganization of healthcare is perceived as a negative phenomenon: management is considered politicized and, therefore, it is not given legitimacy.

Marketization is a euphemism for politicization. ${ }^{1}$ Not in the more noble sense: in the lower sense of division of political power [...]. We liaised with a lot of idiots. Managers who don't know anything about healthcare. But they are required to make ends meet every year, so it is impossible to plan on a longterm basis, as should be necessary in healthcare. Also, [we work with] people without any competence in the health sector. [...]. Italian-style marketization is a contradiction. They are amateurs in both management and healthcare: they are just political party officers. [Neurologist, male, 58].

I think that healthcare corporatization is one of the most illogical contradiction. A balance cannot exist between healthcare access needs and financial rationalization. These concepts cannot get along. They are absolutely antithetical. [Dermatologist, female, 62].

The relation between medical doctors and health management is experienced as conflicting for a twofold reason: firstly, medicine and management rely on antithetical values; secondly, in this perspective health managers are selected for political reasons. For this reason, managers' power is not considered legitimate.

The "liminal" doctor is at the center of the continuum, representing a blended figure of traditional and new issues. A "hybrid" on-the-job logic is displayed, given that professional and organizational logics are combined to reach the same goals (Noordegraaf 2007, 2015; Waring 2015). However, the union of two forms of institutional logic in healthcare is perceived as a problem and reactions vary from passive adaptation to the creation of individual spaces of autonomy complying with organizational rules.

Adaptation to organizational innovations is many-sided and implies several levels of acceptance: some doctors believe that the profession as a whole is degraded in value; others accept it, even though they are aware of the imperatives of this change, such as the need to constantly pay attention to economic aspects of healthcare provision.

\footnotetext{
1 The original Italian term was "partitizzazione", which refers to political parties splitting up their power to affect several dimensions of public domains. In this case, it refers to the introduction of politically selected people in health management.
} 
Clearly, health trusts tend to restrict the free choices of professionals, making an unacceptable interference [...]. The idea I personally acquired is that doctors are now supposed to cope with the aspect of available resources. [Rheumatologist, female, 52].

These doctors are positioned on different places in the middle of the continuum, as they adapt differently: some are closer to the traditional doctor, whereas others are closer to the corporatized doctor. Borders are nuanced and there are no homogeneous reactions to change in terms of practices and mindsets.

In this second approach, traditional professionalism and business-like healthcare are competing logics. However, they coexist, albeit not always harmoniously, because professionals mediate between them trying to combine patients' needs and organizational issues (Blomgren and Waks 2015). This reaction is a reduction of management impositions in everyday work (Tousijn 2013): the acceptance of clinic and organizational guidelines is not complete.

It is necessary to introduce budget limitations up to a certain point and to know how to do them. It is necessary to save money where there is wastefulness; nevertheless patients need to be attended to with dignity. [Cardiologist, female, 53].

I have to give prompt responses to patients [...]. I have a strict schedule, so I have to manage the timetable. I have $20 \mathrm{~min}$ for every patient: this is not fair, but I succeed if I dedicate eight minutes to one patient and 12 to another [...]. But in such an organization it happens that...see? [The doctor shows the results of a clinical examination]. This is a bad and serious result, so you're going to devote more time to this patient. And it is fair, because he or she deserves more time than a patient with no disease, or with an imaginary disease. But the doctor needs time to analyze it. You need more time and it needs to be considered under the point of view of time. Because time is not unlimited; like resources. [Dermatologist, female, 62].

Attending to patients while respecting organizational regulations is crucial. This approach relies on a blend of clinical and administrative skills as combining medical tasks and formal procedures (filling in forms, respecting timetable, etc.) is considered necessary. Performing administrative tasks is integrated into professional work, though it is considered part of the organizational logic instead of the professional one.

Information asymmetry with patients is complex: the single physician is required to be able to understand people, avoiding a paternalistic vision of patients as passive and completely unaware of their health condition.

It is a two-sided coin. Times have changed: there's no longer the patient saying to the doctor: "do whatever you want with me". In my opinion, this is absolutely positive, because people get informed. Nowadays there are various ways of getting informed: you can get all the information you want through using a computer. Often, information is given correctly, I'd say. However, not everybody is able to understand what is important; on the 
other hand, not everybody is able to understand what the incorrect information is. And this is the other side of the coin. Of course, this mechanism increases expenses, because in the past the patient went to the doctor and asked for magnetic resonance just because he read that a little pain needs to be checked through this medical examination. And, some years ago, the doctor said: "here is your referral for the magnetic resonance". Now it is no longer like this [...]. The amount of specialist examinations is now limited and the doctor must cope with this. [Specialist in hygiene and public health, male, 59].

Healthcare is not considered as a hierarchical structure; instead, it is seen as a network of professionals whose center is the doctor and healthcare provision results from the collaboration of professionals involved. There are no higher and lower positions, therefore doctors do not possess the right to tell other professionals how to work; on the contrary, professionals are supposed to exercise autonomy when performing their roles. However, this responsibility does not mean that doctors are in a 'dominant' position in comparison with other health professionals; rather, they represent the center of the professional network and, as such, they become vehicles of information.

The third approach is the corporatized doctor, which occupies the opposite side of the continuum to the traditional doctor; overall, this doctor reacts to change by "co-opting" organizational issues (Waring and Currie 2009). Clinical and organizational guidelines are co-opted in the performance of daily tasks, because they are considered important tools to provide more efficient and cost-effective services.

An "organizing professionalism" is displayed, given that organizational issues become part of professional logic and repertoires (Noordegraaf 2015). Organization is not perceived as an intrusive issue, but it is considered part of professional ethics as both professionals and patients themselves are thought to benefit from it:

If there are guidelines to treat certain pathologies, we have to adapt to them rather than vice-versa, because it simplifies the process. And it's better for the patient. [Guidelines] are compelling reference points to treat several pathologies. So, we need to adapt to them [Oculist, female, 64].

Guidelines are important. Although some of them are aimed at saving resources, their outputs are important because using more homogenous procedures entails better quality, too. [Pediatrician, male, 54].

In this perspective, management skills are considered necessary like clinical and administrative ones: the doctor needs to perform clinical and administrative tasks along with management ones such as budgeting, staffing, measuring performances and problem solving (Phillips and Bullock 2018).

The doctor-patient relationship is considered a partnership and a joint co-production of health. The idea of well-informed patients is seen as a positive thing, instead of a source of problems. Clinicians give some information to patients to guide them, but once patients have been informed, they can make decisions independently. 
It happens that patients have a clear opinion and, maybe, they know even more than you, because they study everything. You just need to take your time and to manage informed patients [...]. Of course, patients could never possess the doctor's knowledge. The doctor is a sort of counsellor and gives information to patients about pathologies and treatments. It is good that patients get information. The doctor needs to consider what patients can understand. Once he or she is aware of that, he or she has to explain things simply to let patients decide. [...] However, doctors and patients are not opposed. [Pediatrician, male, 32].

Likewise, the professionalization of allied health workers is seen as a positive issue: inter-professional relations are based on cooperative forms of logic within a horizontal structure. In this case, no profession is 'pre-eminent' and 'medical dominance' seems to be completely overcome. Every subject has clear professional jurisdiction and skills. For this reason, everybody has the right to work (relatively) autonomously. Everyone is equally important.

Lots of colleagues are afraid of nurses; I am not. Because I think that nurses, as other professionals, have different competences; thus, some duties in the past were in between, such as medications, and sometimes doctors did it, sometimes nurses. Obviously, they are trained for that: they can do medication so much better [...]. We must not be afraid. The doctor is the doctor and will remain the doctor. But it is fair that nurses do some operations, because they can do it better. It is like organizational stuff: it is fair that administrators do it, because they do it better. [...]. There is not a hierarchy among professions. [...] I mean, there are different actors working in parallel, who do different things. [...] In my opinion, the age of the doctor who wants to work alone as a unique professional is over. I mean, he would be a pretentious person without a sense of direction. Doctors cannot work alone. [Pediatrician, male, 32].

The corporatization of healthcare is considered a tool providing increased efficiency to health organizations, since it is assumed that it guarantees better services, improves quality and saves resources. Therefore, the corporatization of healthcare is seen as a positive trend that creates better service provision for patients, becoming part of professional ethos.

The third approach shows a remarkable awareness of corporatized healthcare and of how professionals negotiate values and tasks within the renewed healthcare system. Additionally, it shows that the two logics are not set apart; rather, processes of professional identity reframing emerge, giving way to a coherent self (Bévort and Suddaby 2016) and a new professional ethos.

Taking into consideration the relations with health management, both the second and the third types seem to share the same idea: they are more open to dialogue and available to negotiate with managers. Nevertheless, they consider managers' decisions imposed by other institutions, such as regional governments, government ministries and the European Union, with which professionals must comply. Our data suggest that in both the approaches managers' decisions are accepted, even though we can hypothesize that what it changes is the nature of acceptance: in the case of 
the second type there is a passive acceptance, as it is related to unavoidable imperatives that are not considered directly related to medical professionalism; differently, for the third type acceptance is more convinced as complying with (unavoidable) managers' decisions is considered part of the medical profession.

\section{Discussion and conclusion}

This study aimed to analyse doctors' perceptions of change following the implementation of healthcare reforms in Italy by focusing on territorial healthcare settings. The aim was to examine dynamics involving doctors' professional identities in the framework of the marketization of the Italian NHS, with reference to the Tuscany region. The research aimed to contribute to the debate around doctors' strategic answers to organizational change and the relationship between managerialism and professionalism in healthcare (Numerato et al. 2012; Noordegraaf 2015; Salvatore et al. 2018; Waring 2015). The study focused on the analytical dimensions of physicians' professional identity that it was assumed could be affected by the changes.

The data from the interviews suggest that a reframing of medical professional ethics and mindsets seems to be ongoing within the Tuscany region. The narratives of the professionals provide insights that could be useful to hypothesize a possible re-elaboration of medical professionalism. However, medical professionals' reactions to change seem to be manifold and can vary significantly, such as it happens in hospital settings (Lega and Sartirana 2016; Vicarelli and Pavolini 2017). For this reason, reactions can be positioned on an ideal continuum. Drawing on the data, it is hypothesized that a general change is affecting the perceptions and experiences of doctors working in outpatient settings.

Firstly, the joint analysis of the professional and the organizational dimensions allowed three approaches of physicians to be categorized, corresponding to three types of reaction in the contexts of the field research. Nevertheless, the terms of the continuum are not thorough and a considerable amount of nuances exist between the three ideal-types, which are simply intended to be useful tools to assess the complexity of the change (Weber 1949). In particular, they permitted the observation of a transformation of the professional identities and ethos of doctors working in territorial health organizations, giving account of an ongoing change of medical doctors working logics as a result of the reforms of the public healthcare system. It appears that there is an ongoing reconfiguration of professional identity related to the crucial dimensions taken into consideration. Table 1 offers a summary of the three approaches identified in this study in relation to the analytical dimensions investigated.

The liminal doctor type allowed to hypothesize a nuanced transition of the medical profession. The hybrid logic is displayed in the liminal type, whereas an organizing professionalism in the corporatized type. Hybridity seems to be a liminal condition, as its mindsets and ways of experiencing the medical practice are between two "boundaries", represented by professional and organizational logics. Hybridity does not entail only the introduction of organizational logics into professional ones, but involves a gradual change of ways of thinking and working. The liminal type shows 


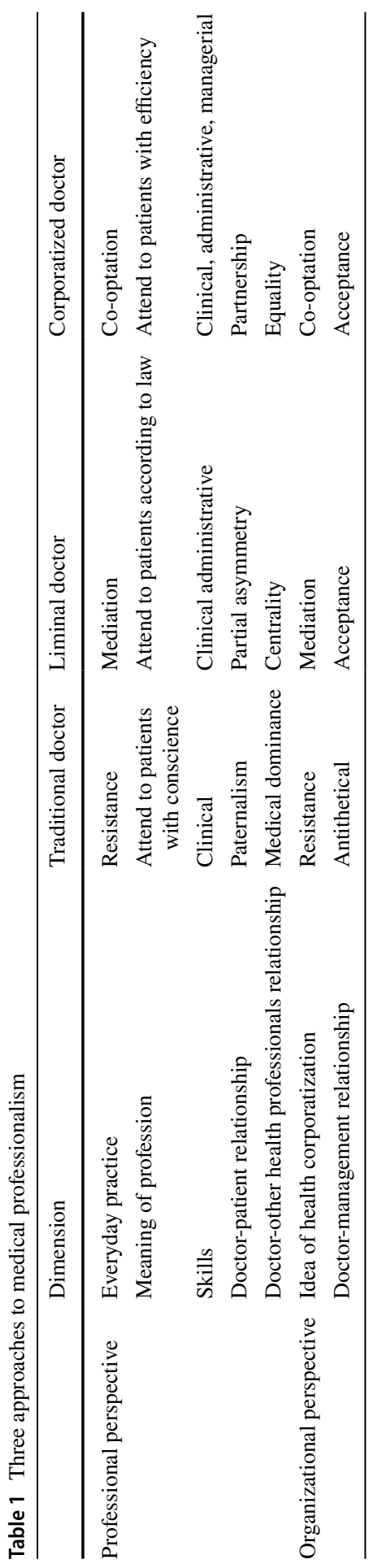

2. 
the nuances of the concept of hybridity and that a professional transition is underway as an "organizing" logic is developing (Noordegraaf 2015). This does not mean that the corporatized approach is a fixed one: the transition is underway and involves both the liminal as well as the corporatized approach.

Secondly, supporting the debate around "hegemony-resistance dualism" (Gleeson and Knights 2006; Salvatore et al. 2018; Tousijn 2013), this study—albeit limited to the context of one region-confirms that the two forms of institutional logic, medical professionalism and business-like healthcare, are not conflicting. Instead, these logics intertwine to create a renewed professional ethos. The joint analysis of professional and organizational dimensions has permitted the observation of new ways to practice the profession of medicine: the traditional logic is mixed up with new organizational issues (McGivern et al. 2015).

In this regard, the findings appear to be in line with theories of change of medical professionalism (Vicarelli and Pavolini 2017), particularly with the concept of 'managing professionalism' (Noordegraaf 2015): in fact, there seems to be a gradual shift from managed professionalism to another kind of medical ethos, which does not simply undergo managerialization. On the contrary, this renewed professionalism tends to accept managerial and organizational issues as part of medical ethics (Berghout et al. 2017). The change does not only concern professional practice; it also seems to involve the professional ethos itself. As Noordegraaf (2015, p. 12) states: "whereas hybrid professionalism is 'meaningfully managed professional work', the move beyond hybridity implies new forms of professionalism in which organizing becomes part of professional work and repertoires. (...) organizing and dealing with tensions is seen as rather normal and natural." Thus, considering the available resources 'naturally' becomes part of everyday work. The findings suggest that this transition seems to involve not only hospital physicians, but also professionals working in outpatient settings.

Significantly, a modification of the Italian medical professional ethics code has introduced principles such as managerial responsibility, clinical appropriateness in healthcare provision and attention to the economic sustainability of the system (Vicarelli 2012). Therefore, organizational dimensions are not seen as issues that a professional is required to cope with. Rather, they are gradually becoming part of the medical professional and it can be assumed that this is particularly applicable for younger professionals.

This study has an important limitation related to the regional dimension, as the field research took place in one Italian region. Considering the regionalization of the Italian healthcare system, it may be assumed that different processes affecting the medical profession in different regional healthcare systems. Consequently, broader survey-based research within different contexts would be useful and could provide more insight into the changes in medical doctors' perceptions and experiences. Moreover, an international comparison of different countries would provide a more definitive picture of the change involving medical doctors and healthcare professionalism (Hartley 2016).

In conclusion, outpatient specialist doctors seem to be a profession in transition, since several dimensions of their professional identity have been affected by the changes. Similarly to Italian hospital doctors (Lega and Sartirana 2016), the reaction 
of these professionals seems to be slow and gradual; yet, a reframing of their professional identity is ongoing. As a result of managerialization processes, the different relationship between medicine and management is contributing to the creation of different ways of practising the profession and new professional values.

Funding Open Access funding provided by Università Politecnica delle Marche within the CRUI-CARE Agreement.

Open Access This article is licensed under a Creative Commons Attribution 4.0 International License, which permits use, sharing, adaptation, distribution and reproduction in any medium or format, as long as you give appropriate credit to the original author(s) and the source, provide a link to the Creative Commons licence, and indicate if changes were made. The images or other third party material in this article are included in the article's Creative Commons licence, unless indicated otherwise in a credit line to the material. If material is not included in the article's Creative Commons licence and your intended use is not permitted by statutory regulation or exceeds the permitted use, you will need to obtain permission directly from the copyright holder. To view a copy of this licence, visit http://creativecommons.org/licen ses/by/4.0/.

\section{References}

Andersson, T., and R. Liff. 2018. Co-optation as a response to competing institutional logics: Professionals and managers in healthcare. Journal of Professions and Organizations 5 (2): 71-87.

Benci, L. 2009. Elementi di legislazione sanitaria e di biodiritto. Milano: McGraw-Hill.

Berghout, M.A., I.N. Fabbricotti, M. Buljac-SamardzÏić, and C. Hilders. 2017. Medical leaders or masters? A systematic review of medical leadership in hospital settings. PLoS ONE 12 (9): 1-24.

Bévort, F., and R. Suddaby. 2016. Scripting professional identities: How individuals make sense of contradictory institutional logics. Journal of Professions and Organizations 3 (1): 18-38.

Bezes, P., D. Demazière, T. Le Bianic, C. Paradeise, R. Normand, D. Benamouzig, F. Pierru, and J. Evetts. 2011. New Public Management et professions dans l'État: au-delà des oppositions, quelles recompositions? New Public Management and professions in the public administration: Beyond opposition, what new patterns are taking shape? Sociologie du travail 53: 295-348.

Blomgren, M., and C. Waks. 2015. Coping with contradictions: Hybrid professionals managing institutional complexity. Journal of Professions and Organizations 2 (1): 78-102.

Carvalho, T. 2014. Changing connections between professionalism and managerialism: A case study of nursing in Portugal. Journal of Professions and Organizations 1 (2): 176-190.

Cascòn-Pereira, R., I. Kirkpatrick, and M. Exworthy. 2016. El estatus de la profesión médica: ¿reforzado o debilitado por la nueva gestión pública? Gaceta Sanitaria 31 (3): 273-275.

Correia, T. 2013. The interplay between managerialism and medical professionalism in hospital organizations from the doctors' perspective: A comparison of two distinctive medical units. Health Sociology Review 22 (3): 255-267.

Denis, J.L., and N. van Gesten. 2016. Medical doctors in healthcare leadership: Theoretical and practical challenges. BMC Health Services Research 16 (2): 158-169.

Doolin, B. 2002. Enterprise discourse, professional identity and the organizational control of hospital clinicians. Organization Studies 23 (3): 369-390.

Dubar, C., and P. Tripier. 1998. Sociologie des professions. Paris: Armand.

Evetts, J. 2006. Short note: The sociology of professional groups. Current Sociology 54 (1): 133-143.

Evetts, J. 2011. A new professionalism? Challenges and opportunities. Current Sociology 59 (2): 406-422.

Filc, D. 2006. Physicians as "organic intellectuals". A contribution to the stratification versus deprofessionalization debate. Acta Sociologica 49: 273-285.

Freidson, E. 1970. Profession of medicine. New York: Harper \& Row. 
Freidson, E. 1986. Professional powers, a study of institutionalizatin of formal knowledge. Chicago: University of Chicago Press.

Freidson, E. 2001. Professionalism. The third logic. On the practice of knowledge. Cambridge: Polity Press.

Freidson, E. 2002. La dominanza medica. Le basi sociali della malattia e delle istituzioni sanitarie. Milano: Franco Angeli.

Giarelli, G. 2003. Il malessere della medicina. Un confronto internazionale. Milano: Franco Angeli.

Giarelli, G. 2019. Il SSN tra paradossi latenti e sostenibilità problematica. In Il Servizio Sanitario Nazionale italiano in prospettiva europea. Un'analisi comparata, ed. G. Giarelli and V. Giovannetti, 15-60. Franco Angeli: Milano.

Gleeson, D., and D. Knights. 2006. Challenging dualism: Public professionalism in "troubled" times. Sociology 40 (2): 277-295.

Hanlon, G. 1999. Lawyers, the state and the market. Professionalism revisited. London: Macmillan Press KTD.

Harrison, S., and W. Ahmad. 2000. Medical autonomy and the UK State 1975 to 2025. Sociology 34 (1): $129-146$.

Hartley, K. 2016. Untangling approaches to management and leadership across systems of medical education. BMC Health Services Research 16 (2): 180-190.

Kelly, S.E. 2010. Qualitative Interviewing Techniques and Styles. In The SAGE Handbook of Qualitative Methods in Health Research, ed. I. Bourgeault, R. Dingvall, and R. de Vries, 289-326. London: Sage.

Kirkpatrick, I., E. Kuhlmann, K. Hartley, M. Dent, and F. Lega. 2016. Medicine and management in European hospitals: A comparative overview. BMC Health Services Research 16 (2): 271-278.

Kuhlmann, E., V. Burau, C. Larsen, R. Lewandoski, C. Lionis, and J. Repullo. 2011. Medicine and management in European healthcare systems: HOW do they matter in the control of clinical practice? The International Journal of Clinical Practice 65 (7): 722-724.

Lega, F., and M. Sartirana. 2016. Making doctors manage... but how? Recent developments in the Italian NHS. BMC Health Services Research 16 (2): 170-177.

Martinussen, P.A., and J. Magnussen. 2011. Resisting market-inspired reform in healthcare: The role of professional subcultures in medicine. Social Sciences \& Medicine 73 (2): 193-200.

McDonald, R., S. Cheraghi-Sohi, S. Bayes, R. Morriss, and J. Kai. 2013. Competing and coexisting logics in the changing field of English general medical practice. Social Science \& Medicine 93: 47-54.

McGivern, R., G. Currie, E. Ferlie, L. Fitzgerald, and J. Waring. 2015. Hybrid manager-professional's identity work: The maintenance of hybridization of medical professionalism in managerial contexts. Public Administration 93 (2): 412-432.

Navarro, V. 1998. Professional dominance or proletarianization? Neither. The Milbank Quarterly 66 (2): 57-75.

Noordegraaf, M. 2007. From "pure" to "hybrid" professionalism. Present-day professionalism in ambiguous public domains. Administration \& Society 39 (6): 761-785.

Noordegraaf, M. 2015. Hybrid professionalism and beyond: (New) Forms of public professionalism in changing organizational and societal contexts. Journal of Professions and Organizations 2 (2): 187-206.

Noordegraaf, M. 2016. Reconfiguring professional work. Changing forms of professionalism in public service provision. Administration \& Society 48 (7): 783-810.

Numerato, D., D. Salvatore, and G. Fattore. 2012. The impact of management on medical professionalism: a review. Sociology of Health and Illness 34 (4): 626-644.

Olakivi, A., and M. Niska. 2017. Rethinking managerialism in professional work: From competing logics to overlapping discourses. Journal of Professions and Organizations 4 (1): 20-35.

Parker, M., and M. Dent. 1996. Managers, doctors, and culture. Changing an English Health District. Administration \& Society 28 (3): 335-361.

Parsons, T. 1939. The professions and social structure. Social forces 17 (4): 457-467.

Pavolini, E., and G. Vicarelli. 2013. Le due Italie della sanità. In Il divario incolmabile Rappresentanza politica e rendimento istituzionale nelle regioni italiane, ed. S. Vassallo, 193-223. Bologna: Il Mulino.

Phillips, S., and A. Bullock. 2018. Clinical leadership training: an evaluation of the Welsh Fellowship programme. Leadership in Health Services 31 (2): 226-237.

Pollitt, C., and G. Bouckaert. 2011. Public management reform. A comparative analysis: New public management, governance, and the neo-weberian state. Oxford: Oxford University Press. 
Reay, T., and C.R. Hinings. 2009. Managing the rivalry of competing institutional logics. Organization Studies 30 (6): 629-652.

Ritzer, G., and D. Walczak. 1988. Rationalization and the deprofessionalization of physicians. Social Forces 67 (1): 1-22.

Sandstrom, R.W. 2007. The meanings of autonomy for physical therapy. Physical Therapy 87 (1): 98-106.

Salvatore, D., D. Numerato, and G. Fattore. 2018. Physicians' professional autonomy and their organizational identification with their hospital. BMC Health Services Research 18: 775.

Spehar, I., J.C. Frich, and L.E. Kjekshus. 2014. Clinicians in management: A qualitative study of managers' use of influence strategies in hospitals. BMC Health Services Research 14: 251.

Tonkens, E., C. Bröer, N. van Sambeek, and D. Van Hassel. 2013. Pretenders and performers: Professional responses to the commodification of health care. Social Theory and Health 11 (4): 368-387.

Tousijn, W. 2008. L'autonomia professionale di fronte alla sfida consumerista e alla sfida manageriale. In I medici in Italia motivazioni, autonomia, appartenenza, ed. L. Speranza, W. Tousijn, and G. Vicarelli, 73-92. Bologna: Il Mulino.

Tousijn, W. 2012. Integrating health and social care: Interprofessional relations of multidisciplinary teams in Italy. Current Sociology 60 (4): 522-537.

Tousijn, W. 2013. Dai mezzi ai fini: il nuovo professionalismo. In Cura e salute. Prospettive sociologiche, ed. G. Vicarelli, 175-197. Roma: Carocci.

Vicarelli, G. 2012. Medici e manager. Verso un nuovo professionalismo? Cambio 3: 126-136.

Vicarelli, G. 2015. Healthcare: Difficult Paths of Reform. In The Italian Welfare State in a European Perspective, ed. U. Ascoli and E. Pavolini. Bristol: Policy Press.

Vicarelli, G. 2017. Si può parlare di declino della professione medica in Italia? Elementi di analisi e riflessione. Autonomie Locali e Servizi Sociali 2: 221-238.

Vicarelli, G. 2019. The creation of the NHS in Italy (1961-1978). Dynamis 39 (1): 43.

Vicarelli, G., and E. Pavolini. 2017. Dynamics between doctors and managers in the Italian National Health Care System. Sociology of Health and Illness 39 (8): 1381-1397.

Waring, J. 2014. Restratification, hybridity and professional elites: Questions of power, identity and relational contingency at the points of "professional-organisational intersection. Sociology Compass 8 (6): 688-704.

Waring, J. 2015. Mapping the public sector diaspora: Towards a model of inter-sectoral cultural hybridity using evidence from the English healthcare system. Public Administration 93 (2): 345-362.

Waring, J., and G. Currie. 2009. Managing expert knowledge: Organizational challenges and managerial futures for the UK medical profession. Organization Studies 30 (7): 755-777.

Weber, M. 1949. The methodology of social sciences. Illinois: Free Press.

Publisher's Note Springer Nature remains neutral with regard to jurisdictional claims in published maps and institutional affiliations.

Federico Sofritti is Postdoctoral Research Fellow at the Department of Economic and Social Sciences of the Polytechnic University of Marche. His research interests include: medical professionalism and healthcare policies; digitalization policies and Industry 4.0; professional identity and precarity. 